\title{
Aerobic power of competitive paraplegic road racers
}

\author{
S P Hooker PhD, C L Wells PhD
}

\section{Exercise and Sport Research Institute, Department of Exercise Science and Physical Education, Arizona State University Tempe, AZ 85287-0404, USA.}

The purpose of this study was to determine peak aerobic power and associated physiological responses in highly competitive spinal cord injured (SCI) paraplegic road racers. Seven (6 male and one female) active paraplegic (lesions T4-T12) road racers and 9 healthy untrained able-bodied males performed continuous graded arm crank ergometer tests to exhaustion for determinations of peak power output $(\mathrm{PO})$, oxygen uptake $\left(\dot{\mathrm{V}}_{2}\right)$, pulmonary ventilation $\left(\dot{\mathrm{V}}_{\mathrm{E}}\right)$, heart rate (HR), and respiratory exchange ratio (RER). Compared to able-bodied subjects, male paraplegic road racers elicited significantly $(p \leqslant .05)$ higher mean $\left( \pm\right.$ SD) peak levels of PO $(141.6 \pm 8.8$ vs $111.4 \pm 27.7 \mathrm{~W})$, absolute $\mathrm{VO}_{2}$ $(2.72 \pm .52$ vs $2.22 \pm .38 \mathrm{l} / \mathrm{min})$, and $\dot{\mathrm{V}} \mathrm{O}_{2}$ per unit of body weight $(43.06 \pm 7.4$ vs $30.33 \pm 4.3 \mathrm{ml} / \mathrm{kg} / \mathrm{min})$. Although peak $\mathrm{HR}(180.3 \pm 9.5$ vs $173.2 \pm 8.5 \mathrm{bpm})$ and VE $(92.8 \pm 17.2$ vs $74.6 \pm 20.3 \mathrm{l} / \mathrm{min})$ tended to be higher for male paraplegic road racers than able-bodied subjects, the differences were not statistically significant. The female paraplegic road racer achieved the highest peak levels of PO $(119 \mathrm{~W})$ and $\dot{\mathrm{VO}}{ }_{2}(1.99 \mathrm{l} / \mathrm{min} ; 38.0 \mathrm{ml} / \mathrm{kg} / \mathrm{min})$ reported to date for wheelchair-dependent women. These data suggest that intense physical training via wheelchair propulsion can markedly enhance upper body cardiovascular fitness in SCI paraplegics. However, the correlational analysis between $10 \mathrm{~km}$ time and peak $\mathrm{VO}_{2}$ was nonsignificant $(p>.05)$ indicating that factors other than peak upper body aerobic power may influence wheelchair road racing performance.

Key words: aerobic fitness; oxygen uptake; paraplegia; spinal cord injured; upper body exercise; wheelchair athlete.

\section{Introduction}

One of the most widely recognized and publicized wheelchair sports events in recent years has been wheelchair road racing. The offering of prize money to successful performers in wheelchair road racing competition has prompted greater participation by wheelchair-dependent individuals in this particular sport, as well as the implementation of more specialized and rigorous training programs for wheelchair road racers. ${ }^{1}$ To date, the largest contingent of wheelchair road racers is comprised of spinal cord injured (SCI) persons. Each of the aforementioned factors has contributed to the

Correspondence: Department of Physical Therapy, University of Southern California, 2025 Zonal Ave., CSA 208, Los Angeles, CA 90033, USA. generation of more research involving the physiological responses of SCI persons to upper extremity exercise.

Recent studies ${ }^{2-7}$ evaluating the peak upper body aerobic power of endurancetrained SCI athletes reveal the strong interest that the international research community has in this athletic population. However, these studies have generally involved either wheelchair track athletes ${ }^{2,3}$ or marathoners. ${ }^{5,6}$ To our knowledge, little attention has been given to well trained and highly competitive wheelchair road racers whose most common racing distance is $10 \mathrm{~km}$. The purpose of this study was, therefore, to compare the aerobic power and associated peak physiological responses of active male SCI wheelchair road racers to healthy, but untrained, male able bodied subjects during maximal effort upper body 
exercise. In addition, since exercise performance data on women wheelchair athletes in general are scarce, the peak physiological responses to upper extremity exercise are also reported for one elite women SCI wheelchair road racer.

\section{Subjects and methods}

Six male SCI paraplegics and one woman SCI paraplegic with lesion levels ranging from T4 to T12 volunteered to participate in the study. Table I lists the personal characteristics of the SCI subjects. Each subject had suffered a traumatic spinal cord injury, and 5 were diagnosed as neurologically complete with respect to the loss of infralesional motor function. Each subject was an active participant in the 1987 Invacare Cup Road Racing Series which consisted of 7 races held throughout the United States over a 12-month period. Based on the International Stoke Mandeville Games Federation classification system,${ }^{8} 3$ subjects were class II athletes, 2 were class III althletes, and 2 were class IV athletes. At the time of data collection, this SCI group included the men and women wheelchair athletes with the current world record times for the $10 \mathrm{~km}$ distance. Nine healthy, moderately active, but aerobically untrained males volunteered to serve as a comparison group. Written informed consent and complete health and activity histories were obtained from each subject prior to their participation in accordance with guidelines established by the University Human Subject Research Review Committee.

Testing occurred while the SCI athletes were in Phoenix, AZ for the sixth event of the 1987 Invacare Cup Road Racing Series. This race was to be $10 \mathrm{~km}$ in distance, but was cancelled due to rain. Thus, the elements of muscle fatigue or soreness that commonly occur after competitive wheelchair road races were not a factor during subsequent test sessions.

Each subject completed a continuous, progressive intensity arm crank ergometer (ACE) test to exhaustion. The ACE (Monark Rehab Trainer ${ }^{\mathrm{TM}}$, Monark-Crescent AB, Varberg, Sweden) was mounted on a metal frame similar to that previously described. ${ }^{9}$ Prior to exercise, the crank axle was positioned at mid sternum level, with slight elbow flexion when the arm was in the extended position. This allowed for standard placement of the ACE among subjects.

The test protocol required the subjects to maintain a target cadence of $70 \mathrm{rpm}$. A visual display of rpm was provided to each subject during all tests. The initial power output (PO) of $17 \mathrm{~W}$ was increased by $17 \mathrm{~W}$ every 2 minutes. The test was terminated when the subjects reached exhaustion, or if the cadence fell below $65 \mathrm{rpm}$. Investigators provided verbal encouragment to the sub-

Table I Characteristics of the spinal cord injured road racers

\begin{tabular}{cccccccc}
\hline Subject & Gender & $\begin{array}{c}\text { Age } \\
(\mathrm{yr})\end{array}$ & $\begin{array}{c}\text { Weight } \\
(\mathrm{kg})\end{array}$ & Lesion & YSI & $\begin{array}{c}10 \mathrm{~km} \text { time } \\
(\mathrm{min}: \mathrm{sec})+\end{array}$ & Class \\
\hline 1 & $\mathrm{M}$ & 37 & 69.6 & T4 & 14 & $27: 17$ & II \\
2 & $\mathrm{M}$ & 33 & 58.0 & T4 & 30 & $25: 20$ & II \\
3 & $\mathrm{M}$ & 29 & 60.8 & T5i & 14 & $24: 17^{*}$ & II \\
4 & $\mathrm{~F}$ & 33 & 52.4 & T10 & 13 & $27: 21^{*}$ & III \\
5 & $\mathrm{M}$ & 40 & 61.4 & T12 & 14 & $28: 20$ & III \\
6 & $\mathrm{M}$ & 28 & 61.9 & T10 & 8 & $29: 23$ & IV \\
7 & $\mathrm{M}$ & 45 & 67.2 & T12i & 14 & $25: 53$ & IV \\
\hline
\end{tabular}

YSI = years since injury

$\mathrm{i}=$ incomplete spinal cord injury

+ represents best $10 \mathrm{~km}$ time for current (1987) Invacare Cup road racing season

*World record $10 \mathrm{~km}$ wheelchair racing time (at the time of study) 
jects to continue exercising as long as possible. A 10-minute rest period followed the onset of exhaustion, after which a 'supramaximal' protocol was administered to verify the attainment of peak oxygen uptake $\left(\mathrm{V}_{2}\right)$. During this protocol, the subjects exercised at a moderate PO for 2 minutes followed immediately by 2 minutes of $\mathrm{ACE}$ exercise at a $\mathrm{PO}$ equal to $17 \mathrm{~W}$ plus the $\mathrm{PO}$ at exhaustion.

Metabolic and cardiopulmonary data were collected on-line in 30-second segments with a microcomputer using a metabolic measurement program ( $\mathrm{S} \& \mathrm{M}$ Instrument Co, Doylestown, PA). Pulmonary ventilation $\left(\dot{V}_{E}, 1 / \mathrm{min}\right)$ was calculated from expired volume with a calibrated pressuresensitive pneumotach. The subjects breathed through a two-way Daniels valve into a 5-litre mixing chamber, from which a sample of air was continuously drawn. Applied Electrochemistry S-3A and Beckman LB-2 analyzers were used to determine the oxygen and carbon dioxide $\left(\mathrm{CO}_{2}\right)$ content of the expired air, respectively. Heart rate (HR, bpm) was continuously monitored with a Hewlett-Packard oscilloscope-cardiotachometer and recorded during the final 15 seconds of each exercise stage. Peak $\dot{\mathrm{VO}}_{2}(\mathrm{l} / \mathrm{min}), \dot{\mathrm{V}}_{\mathrm{E}}$, and respiratory exchange ratio (RER; $\dot{\mathrm{V} C \mathrm{C}_{2}} / \mathrm{VO}_{2}$ ) were determined for each exercise stage by averaging the last 230 -second values. Peak values for $\mathrm{PO}$ and physiological variables were defined as the highest level achieved during either the initial ACE test to exhaustion or the 'supramaximal' protocol.

Only data from the 6 male SCI athletes were included in the statistical tests for comparisons with the able bodied comparison group. Mean values for age, body weight, and peak $\dot{\mathrm{V}} \mathrm{O}_{2}, \dot{\mathrm{V}}_{\mathrm{E}}, \mathrm{HR}$, RER, and PO were compared between groups with separate one-way analyses of variance. Spearman-rho rank order correlations were derived to determine relationships between lesion level and peak $\mathrm{VO}_{2}$ and lesion level and $10 \mathrm{~km}$ time. A Pearson-Product Moment correlation was calculated to determine the relationship between peak $\dot{\mathrm{VO}}_{2}$ and $10 \mathrm{~km}$ time. Since the Phoenix AZ race was cancelled, an up-to-date $10 \mathrm{~km}$ time was unavailable. Since not all of the subjects had competed in a previous race simultaneously, the best $10 \mathrm{~km}$ time within the current racing season was obtained from each SCI subject and used in the correlational analyses. The criterion level of significance was pre-established as $p \leqslant .05$. All data are presented as means \pm standard deviation (SD).

\section{Results}

\section{Training regime information and $10 \mathrm{~km}$ performance}

The mean training duration for this SCI group was $6.7 \pm 4.0$ years. The mean best $10 \mathrm{~km}$ time for current (1987) racing season for the male paraplegic road racers was $26.7 \pm 1.9$ minutes. The best $10 \mathrm{~km}$ time for the female paraplegic road racer was a world record time of 27.3 minutes. Training practice data revealed that these SCI athletes averaged $121.1 \pm 20.8 \mathrm{~km}$ of wheelchair propulsion training per week. Training included organized sessions of speed, interval, hill, and long slow distance protocols. Three of the SCI road racers also participated in a regular upper body weight training program, and the woman road racer implemented wheelchair roller exercise on a weekly basis. Individual training programs are summarized in Table II.

\section{Comparison of male SCI road racers to untrained able bodied males}

The male paraplegic road racers were significantly older than the able bodied male subjects $(35.3 \pm 6.6$ vs $23.0 \pm 3.9 \mathrm{yr})$. As a group, the able bodied male subjects were $10 \mathrm{~kg}$ heavier in body weight than the SCI males $(63.2 \pm 4.3$ vs $73.4 \pm 10.0 \mathrm{~kg})$. However, there was no significant difference in body weight between these groups due to the larger variability in body weight among the male able bodied subjects.

Table III lists the peak levels of PO and physiological responses attained by the male SCI road racers and able bodied subjects during maximal effort ACE exercise. Table IV gives the peak physiological responses during exhaustive upper extremity exercise in the present SCI subject group and endurance-trained SCI athletes from studies since 1986. Compared to the able bodied 
Table II Training practices of the spinal cord injured road racers

\begin{tabular}{|c|c|}
\hline Subject & Weekly Training Practices \\
\hline 1 & $\begin{array}{l}\text { hills } 2 \times / \mathrm{wk} \text {; intervals } 2 \times / \mathrm{wk} \text {; long } \\
\text { slow distance } 2 \times / \mathrm{wk} \text {; off } 1 \times / \mathrm{wk} \text {; } \\
96-160 \mathrm{~km} / \mathrm{wk}\end{array}$ \\
\hline 2 & $\begin{array}{l}\text { speed work } 1 \times / \text { wk; intervals } 2 \times / \mathrm{wk} \text {; } \\
\text { long slow distance } 2 \times / \mathrm{wk} \text {; off } 2 \times / \mathrm{wk} \text {; } \\
64-96 \mathrm{~km} / \mathrm{wk}\end{array}$ \\
\hline 3 & $\begin{array}{l}\text { speed work } 4 \times / \text { wk; intervals } 1 \times / \text { wk; } \\
\text { long slow distance } 1 \times / \text { wk; weights } \\
1 \times / \text { wk }\end{array}$ \\
\hline 4 & $\begin{array}{l}\text { hills } 1-3 \times / \mathrm{wk} ; \text { speed work } 1-3 \times / \mathrm{wk} \text {; } \\
\text { rollers } 2 \times / \mathrm{wk} \text {; long slow distance } \\
3 \times / \mathrm{wk} ; \text { weights } 2 \times / \mathrm{wk}\end{array}$ \\
\hline 5 & $\begin{array}{l}\text { intervals } 1 \times / \mathrm{wk} \text {; speed work } 1 \times / \mathrm{wk} \text {; } \\
\text { hills } 1 \times / \mathrm{wk} ; \text { long slow distance } \\
1 \times / \mathrm{wk} ; 64-112 \mathrm{~km} / \mathrm{wk}\end{array}$ \\
\hline 6 & $\begin{array}{l}\text { long slow distance } 4-5 \times / \mathrm{wk} \text {; } \\
80-112 \mathrm{~km} / \mathrm{wk}\end{array}$ \\
\hline 7 & $\begin{array}{l}\text { intervals } 1-2 \times / \text { wk; hills } 1-2 \times / \text { wk; } \\
\text { speed work } 1-2 \times / \text { wk; long slow dis- } \\
\text { tance } 2-3 \times / w k ; \text { weights } 3-4 \times / \mathrm{wk} \text {; } \\
128-176 \mathrm{~km} / \mathrm{wk}\end{array}$ \\
\hline
\end{tabular}

$\times / \mathrm{wk}=$ times per week

$\mathrm{km} / \mathrm{wk}=$ kilometers per week

group, the male paraplegic road racers achieved significantly higher levels of peak $\mathrm{PO}$, absolute $\dot{\mathrm{V}} \mathrm{O}_{2}$, and $\dot{\mathrm{V}} \mathrm{O}_{2}$ expressed per unit of body weight. Peak HR and $\dot{V}_{E}$ also tended to be higher for the male SCI athletes, but statistical significance was not obtained. There was no significant difference between groups for peak RER.
Five of the 6 male paraplegics and each able bodied subject had either a minor increase $(20 \mathrm{ml} / \mathrm{min}$ or less $)$ or a decrease in $\dot{\mathrm{V}} \mathrm{O}_{2}$ during the 'supramaximal' protocol compared to the $\dot{\mathrm{V}} \mathrm{O}_{2}$ elicited at the initial point of exhaustion. The plateau in $\dot{\mathrm{VO}}_{2}$ combined with RER values well above unity (range 1.04-1.30) indicated that these subjects obtained their 'true' ACE peak $\mathrm{V}_{2}$. One SCI male exhibited a $230 \mathrm{ml} / \mathrm{min}$ increase in $\dot{\mathrm{VO}}_{2}$ during the 'supramaximal' protocol combined with a high RER of 1.25.

\section{Peak physiological responses of the woman SCI road racer \\ The woman paraplegic road racer attained peak PO, absolute $\mathrm{VO}_{2}$, relative $\dot{\mathrm{VO}}_{2}, \dot{\mathrm{V}}_{\mathrm{E}}$, and $\mathrm{HR}$ values of $102 \mathrm{~W}, 1.99 \mathrm{l} / \mathrm{min}$, $38.0 \mathrm{ml} / \mathrm{kg} / \mathrm{min}, 69.8 \mathrm{l} / \mathrm{min}$, and $167 \mathrm{bpm}$, respectively. The peak values for physiolo- gical responses achieved by this subject during maximal effort ACE exercise are displayed in Table $\mathrm{V}$. The woman SCI athlete exhibited a $20 \mathrm{ml} / \mathrm{min}$ decrease in $\dot{\mathrm{V}} \mathrm{O}_{2}$ and a RER of 1.12 during the supra- maximal protocol indicating valid attain- ment of ACE peak $\mathrm{V}_{2}$.}

\section{Relationships among lesion level, peak $\dot{\mathrm{VO}} \mathrm{O}_{2}$, and $10 \mathrm{~km}$ time}

No significant relationships were found between lesion level and peak $\dot{\mathrm{V}} \mathrm{O}_{2}(\mathrm{r}=0.00)$, lesion level and $10 \mathrm{~km}$ time $(\mathrm{r}=0.38)$, or peak $\mathrm{V}_{2}$ and $10 \mathrm{~km}$ time $(\mathrm{r}=-0.06)$.

Table III Peak levels of power output and physiological responses attained during maximal effort arm crank ergometer tests

\begin{tabular}{lcc}
\hline & $\begin{array}{c}\text { Male paraplegic } \\
\text { road racers }(n=6)\end{array}$ & $\begin{array}{c}\text { Able bodied } \\
\text { subjects }(\mathrm{n}=9)\end{array}$ \\
\hline Power output $(\mathrm{W})$ & $141.7 \pm 8.8$ & $111.4 \pm 22.7^{*}$ \\
Oxygen uptake $(\mathrm{l} / \mathrm{min})$ & $2.72 \pm 0.52$ & $2.22 \pm 0.38^{*}$ \\
Oxygen uptake $(\mathrm{ml} / \mathrm{kg} / \mathrm{min})$ & $43.1 \pm 7.4$ & $30.3 \pm 4.3^{*}$ \\
Pulmonary ventilation $(\mathrm{l} / \mathrm{min})$ & $92.8 \pm 17.2$ & $74.6 \pm 20.3$ \\
Heart rate $(\mathrm{bpm})$ & $180.3 \pm 9.5$ & $173.2 \pm 8.5$ \\
Respiratory exchange ratio & $1.16 \pm 0.09$ & $1.22 \pm 0.07$ \\
\hline
\end{tabular}

Values are mean $\pm \mathrm{SD}$

*significant difference between paraplegic road racers and ablebodied subject $(p \leqslant .05)$. 
Table IV Peak physiological responses elicited in endurance-trained male paraplegic athletes in studies since 1986 and the present study

\begin{tabular}{|c|c|c|c|c|c|c|c|}
\hline Reference & $\mathrm{N}$ & $\begin{array}{l}\text { Age } \\
(\mathrm{yr})\end{array}$ & $\begin{array}{l}\text { Lesion } \\
\text { level }\end{array}$ & $\begin{array}{l}\text { Test } \\
\text { mode }\end{array}$ & $\begin{array}{c}\dot{\mathrm{V} \mathrm{O}_{2}} \\
(\mathrm{l} / \mathrm{min})\end{array}$ & $\begin{array}{c}\dot{\mathrm{V} \mathrm{O}_{2}} \\
(\mathrm{ml} / \mathrm{kg} / \mathrm{min})\end{array}$ & $\begin{array}{l}\text { Heart rate } \\
\quad(\mathrm{bpm})\end{array}$ \\
\hline urk & 4 & $.8 \pm$ & $\mathrm{T} 3-$ & WERG & $2.12 \pm$ & $28.1 \pm$ & 163 \\
\hline $\begin{array}{l}\text { Coutts and } \\
\text { Stogryn }^{2}\end{array}$ & 2 & 5 & T9 & WERG & . & 0 & \\
\hline Eriksson et $a^{3}{ }^{3}$ & 5 & $39.0 \pm 5.0$ & $\mathrm{~T} 4-\mathrm{T} 7$ & ACE & $1.20 \pm 0.10$ & $17.4 \pm 2.2$ & $165 \pm 10$ \\
\hline Erikss & 4 & $37.0 \pm$ & T12- & $\mathrm{ACE}$ & $40 \pm$ & $34.7 \pm$ & 182 \\
\hline Flandrois et $\mathrm{al}^{4}$ & 17 & $31.0 \pm$ & $\mathrm{T} 10-\mathrm{T} 12$ & $\begin{array}{l}\text { WC on } \\
\text { rollers }\end{array}$ & $2.16 \pm$ & $33.6 \pm 6.7$ & 13 \\
\hline $\begin{array}{l}\text { Gass and } \\
\text { Camp }\end{array}$ & 6 & $27.5 \pm 2.3$ & $\mathrm{~T} 10$ & WC on TM & $2.86 \pm 0.17$ & $47.5 \pm 4.4$ & $190 \pm 2$ \\
\hline Okuma et & 8 & $30.8 \pm$ & $\mathrm{T} 7$ & W & & 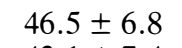 & 1 \\
\hline Present & 6 & $5.3 \pm 6.6$ & $\mathrm{~T} 4-\mathrm{T} 12$ & ACE & $2.72 \pm$ & $43.1 \pm 7.4$ & $180 \pm 10$ \\
\hline
\end{tabular}

Values are mean \pm SD

* value calculated from available data

WERG = wheelchair ergometry

$\mathrm{ACE}=$ arm crank ergometry

$\mathrm{WC}=$ wheelchair

$\mathrm{TM}=$ treadmill

\section{Discussion}

As indicated by the best $10 \mathrm{~km}$ times (Table I), the SCI group comprised Open Division wheelchair road racers of elite status. The mean best $10 \mathrm{~km}$ racing speed for the male paraplegics was $6.25 \mathrm{~m} / \mathrm{sec}$. This mean racing speed exceeds and approaches the individual world record $5000 \mathrm{~m}(5.75 \mathrm{~m} / \mathrm{sec})$ and marathon $(6.40 \mathrm{~m} / \mathrm{sec})$ speeds, respectively, recently reported for male paraplegics. ${ }^{10}$ The woman paraplegic road racer's best $10 \mathrm{~km}$ speed was $6.08 \mathrm{~m} / \mathrm{sec}$ which is noticeably faster than the individual world record $5000 \mathrm{~m}$ speed $(4.67 \mathrm{~m} / \mathrm{sec})$ recorded previously by a woman paraplegic. ${ }^{10}$ This SCI group's motivation for athletic excellence is reflected in their dedication to rigorous and sophisticated training regimes. Indeed, training practices of the SCI athletes in the present study (Table II) are similar to those previously reported for other elite wheelchair-dependent road racers. ${ }^{1}$

The male SCI road racers elicited a significantly higher (by 18\%) peak $\dot{\mathrm{VO}}_{2}$ than the male able bodied group during maximal effort ACE exercise. It has been previously demonstrated that arm volume and arm strength contribute to ACE peak
PO achieved by able bodied subjects. ${ }^{11}$ The difference in peak upper body aerobic power between groups may, therefore, be due to the $27 \%$ higher $\mathrm{PO}$ achieved by the paraplegic road racers as a result of enhanced upper body muscle strength and muscle endurance via intense wheelchair propulsion training. Unfortunately, measures of arm strength were not obtained in this study. It has also been stated that peripheral (ie muscular), rather than central (ie cardiovascular) training adaptations are more likely to occur during training with small upper body muscle groups. ${ }^{4,12-14}$ However, the capacity for male paraplegic road racers to achieve a higher upper body peak aerobic power than male able bodied subjects via augmented central circulatory function cannot be completely excluded. Davis et al ${ }^{15}$ observed significant increases in peak left ventricular stroke volume (SV) and cardiac output (Q) in previously untrained paraplegics following 16 weeks of aerobic ACE training. Comparisons of upper body peak SV and $Q$ have not been conducted before and after wheelchair propulsion training nor between SCI athletes and able bodied subjects. These data 
Table $\mathbf{V}$ Peak physiological responses elicited in able bodied and paraplegic women subjects in previous studies and the present study

\begin{tabular}{|c|c|c|c|c|c|c|c|}
\hline Reference & $\mathrm{N}$ & $\begin{array}{l}\text { Age } \\
(\mathrm{yr})\end{array}$ & $\begin{array}{l}\text { Lesion } \\
\text { level }\end{array}$ & $\begin{array}{l}\text { Test } \\
\text { mode }\end{array}$ & $\begin{array}{c}\dot{\mathrm{V}} \mathrm{O}_{2} \\
(\mathrm{l} / \mathrm{min})\end{array}$ & $\begin{array}{c}\dot{\mathrm{V} \mathrm{O}_{2}} \\
(\mathrm{ml} / \mathrm{kg} / \mathrm{min})\end{array}$ & $\begin{array}{l}\text { Heart rate } \\
\quad \text { (bpm) }\end{array}$ \\
\hline Fitzgerald et $a l^{21}$ & 5 & $24.6 \pm 1.2$ & $\mathrm{AB}$ & WERG & $1.48 \pm 0.48$ & $22.9 *$ & - \\
\hline Sedlock et $a l^{24}$ & 9 & $24.0 \pm 2.3$ & $\mathrm{AB}$ & $\mathrm{ACE}$ & $1.27 \pm 0.36$ & $21.7^{*}$ & $161 \pm 18$ \\
\hline Vander et al $^{23}$ & 10 & $28.8 \pm 4.3$ & $\mathrm{AB}$ & $\mathrm{ACE}$ & $1.60 \pm 0.26$ & $27.7 \pm 5.3$ & $169 \pm 12$ \\
\hline Burkett et al ${ }^{18}$ & 5 & $29.0 \pm 7.3^{*}$ & $\mathrm{~T} 4-\mathrm{T} 10$ & WERG & $0.87 \pm 0.18^{*}$ & $15.9 \pm 2.2$ & $166 \pm 25^{*}$ \\
\hline $\begin{array}{l}\text { Coutts and } \\
\text { Strogryn }^{2}\end{array}$ & 1 & 22 & $\mathrm{~T} 10 / 11$ & WERG & 1.42 & 28.9 & 192 \\
\hline Fitzgerald et al 21 & 5 & $27.0 \pm 1.7$ & T9-L4 & WERG & $1.14 \pm 0.10$ & 19.34* & - \\
\hline Morris 20 & 1 & 25 & $\mathrm{~T} 3 / 4$ & $\mathrm{ACE}$ & 1.32 & 20.3 & 161 \\
\hline Tahamont et al 22 & 6 & $27.3 \pm 6.4$ & T10-L4 & WERG & $0.90 \pm 0.11$ & $14.8 \pm 2.5$ & $150 \pm 27$ \\
\hline Vander et $a l^{23}$ & 7 & $34.0 \pm 10.0$ & $\mathrm{~T} 1-\mathrm{T} 12$ & ACE & $0.77 \pm 0.11$ & $14.0 \pm 1.4$ & $172 \pm 13$ \\
\hline Present study & 1 & 33 & $\mathrm{~T} 10$ & ACE & 1.99 & 38.0 & 167 \\
\hline
\end{tabular}

Values are mean \pm SD

*value calculated from available data

$\mathrm{AB}=$ able-bodied

$\mathrm{WERG}=$ wheelchair ergometry

$\mathrm{ACE}=$ arm crank ergometry

need to be collected before definitive statements regarding the peripheral muscular and central circulatory contributions to upper body peak aerobic power in SCI paraplegics can be made.

Previous comparisons of peak aerobic power have depicted similar levels of cardiopulmonary fitness in SCI athletes and untrained able bodied subjects. ${ }^{3,4}$ These findings contrast with results of the present study showing markedly higher upper body peak $\dot{\mathrm{VO}}_{2}$ in highly competitive SCI paraplegic road racers than untrained able bodied persons. The reason(s) for discrepancy between studies is known. However, less vigorous aerobic training practices, higher lesion levels, less functional upper body muscle mass, or less subject motivation may have contributed to the lower upper body peak aerobic power in SCI athletes of previous studies. The upper body cardiovascular fitness level of the sedentary able bodied group in the present study is similar to that observed for other sedentary able bodied populations. ${ }^{16}$ A lower-than-normal upper body peak $\mathrm{VO}_{2}$ in the present able bodied group, therefore, does not account for the differences between studies. In support of the present study, an extensive review of the literature indicated that low lesion paraplegic endurance athletes generally exhibit higher levels of upper body cardiovascular fitness than age-matched sedentary able bodied subjects. ${ }^{17}$

The mean peak $\dot{\mathrm{VO}}_{2}$ for male paraplegic road racers in this study is comparable to those recently reported for Australian, ${ }^{5}$ Canadian $^{2}$ and Japanese ${ }^{6}$ male paraplegic racers (Table IV); higher than those depicted for Swedish ${ }^{3}$ and French ${ }^{4}$ male paraplegic racers (Table IV); and considerably greater than that determined for aerobically untrained male SCI paraplegics., 3,17-19 The direct comparison in peak aerobic power with the present able bodied group, as well as indirect comparisons with other wheelchair-dependent subjects indicate that upper body exercise training can promote substantial improvements in cardiopulmonary fitness in SCI persons. However, the ACE peak $\mathrm{VO}_{2}$ attained in the present group of elite SCI athletes does not approach ACE peak $\mathrm{VO}_{2}$ levels achieved by upper body endurance-trained able bodied athletes. ${ }^{16}$ There may be a physiological limit to the upper body peak aerobic power attainable by SCI paraplegics due to (1) a large inactive muscle mass due to paralysis below the lesion level (especially in high lesion paraplegics), ${ }^{4}$ and/or (2) the presence of 
hypokinetic circulation during upright upper body exercise attributable to sympathetic dysfunction resulting from spinal cord injury. ${ }^{13}$

Interestingly, the woman paraplegic road racer achieved a $27 \%$ higher peak aerobic power in $\mathrm{ml} / \mathrm{kg} / \mathrm{min}$ than the able bodied men. Her peak $\dot{V}_{2}$ of $38.0 \mathrm{ml} / \mathrm{kg} / \mathrm{min}$ was higher than the individual peak $\mathrm{VO}_{2}$ elicited by 8 of the 9 able bodied male subjects and her absolute peak $\dot{\mathrm{VO}}_{2}$ of $1.99 \mathrm{l} / \mathrm{min}$ was only $230 \mathrm{ml} / \mathrm{min}$ lower than the mean absolute peak $\dot{\mathrm{VO}}_{2}$ for able bodied men. The extraordinary upper body cardiovascular fitness level of this woman SCI athlete is clearly apparent when comparing her to previously studied wheelchair-dependent and able bodied women (Table V). The peak $\dot{\mathrm{V}} \mathrm{O}_{2}$ of the woman paraplegic road racer in the present study is markedly higher than that previously reported for trained SCI women, ${ }^{2,20}$ untrained SCI women, ${ }^{18,21-23}$ and untrained able bodied women. ${ }^{23,24}$ The striking difference in peak aerobic power between this highly competitive woman paraplegic road racer and other SCI and able bodied women further supports the notion that wheelchair exercise training can substantially improve upper body cardiopulmonary fitness in SCI persons. Indeed, the training regime of this SCI athlete (subject 4 , Table II) was one of the most rigorous and well balanced programs observed for any of the SCI road racers studied.

Previous studies have noted a significant relationship between lesion level and physical working capacity ${ }^{25}$ and lesion level and upper body cardiopulmonary fitness $3,4,8,18,26$ in wheelchair-dependent persons. Individuals with lower lesion levels generally have more available functional muscle mass which results in higher peak power output ${ }^{25}$ and aerobic power ${ }^{26}$ during exhaustive upper body exercise. The relatively small sample size, heterogeneity in completeness of injury, similarity in training practices among the paraplegic road racers, and exclusion of quadriplegic subjects reduced the probability of obtaining a significant correlation between lesion level and ACE peak $\mathrm{VO}_{2}$ in the present study. However, the highest peak $\dot{\mathrm{VO}}_{2} \quad(3.65 \mathrm{l} / \mathrm{min}$; $54.8 \mathrm{ml} / \mathrm{kg} / \mathrm{min}$ ) was elicited by a male paraplegic (subject 7) with the lowest lesion level (T12). To our knowledge, this is the highest individual peak aerobic power reported for a male paraplegic to date. This subject was also, at age 45 , one of the older paraplegic athletes tested to date.

Lesion level was also not well correlated with $10 \mathrm{~km}$ time. This finding agrees with results documenting that wheelchair racing speed did not become faster as the level of disability became less in paraplegic track athletes. ${ }^{10}$ Hedrick et al ${ }^{1}$ also observed that disability level was not predictive of the SCI athlete's elite status as a wheelchair road racer. It was determined by Hedrick et al ${ }^{1}$ that the training programs of SCI athletes whose best $10 \mathrm{~km}$ times were one standard deviation faster than other Open Division competitors were generally characterized by greater consistency and intensity. The road racers in the present investigation (a self selected subject group) had similar training regimes, as well as similar wheelchair $10 \mathrm{~km}$ performances. Together, the present and former findings suggest that, with implementation of the appropriate training practices, SCI paraplegics of varying lesion level can compete equitably in wheelchair road racing events.

The current study also revealed a nonsignificant correlation between ACE peak $\dot{\mathrm{V}} \mathrm{O}_{2}$ and $10 \mathrm{~km}$ time, both of which exhibited a relatively narrow range of values. It is not known if high ACE cardiopulmonary fitness translates to successful wheelchair exercise performance. However, within the limitations of this study, it appears that upper body peak aerobic power is not the primary factor influencing wheelchair road racing performance in events lasting 24-30 minutes. Similar data have been presented for competitive able bodied $10 \mathrm{~km}$ runners who were homogeneous with respect to maximal $\dot{\mathrm{V}}_{2}$ obtained during treadmill exercise. ${ }^{27}$ Interestingly, subject 3 , the male $10 \mathrm{~km}$ world record holder at the time of this study, had a T5 lesion (class II) and the lowest measured peak $\dot{\mathrm{VO}}_{2}$ among the six male SCI road racers. Subject 6 (T10 lesion level/class IV) exhibited the second highest ACE peak $\mathrm{VO}_{2}$ among the male paraplegics, yet reported the slowest best $10 \mathrm{~km}$ time. For subjects in the present study, 
there was a clear dissociation between $\mathrm{ACE}$ peak $\dot{\mathrm{VO}}_{2}$ and $10 \mathrm{~km}$ wheelchair racing performance. Further investigation of the following variables may yield information as to which factors limit wheelchair road racing performance: genetic endowment, upper body muscle strength, physical fitness/activity level prior to spinal cord injury, training practices employed, upper body anaerobic power, nutritional practices, wheelchair racing experience, wheelchair propulsion economy, wheelchair propulsion biomechanics, wheelchair design (eg pushrim diameter, number of wheels, steering mechanisms), and psychological status.

\section{Conclusion}

The data indicate that chronic, intense wheelchair propulsion exercise training can enhance upper body cardiopulmonary fitness to levels higher than demonstrated for healthy, untrained able bodied persons. It also appears that consistent and rigorous wheelchair propulsion exercise training may offset differences in disability enabling SCI paraplegics of varying lesion level to compete equally in wheelchair road racing. The lack of a significant relationship between ACE peak aerobic power and $10 \mathrm{~km}$ time strongly suggests that factors other than upper body cardiopulmonary fitness influence wheelchair road racing performance. However, more extensive research is required to isolate the factors that contribute most to successful wheelchair road racing performance.

\section{Acknowledgements}

The authors wish to thank the subjects for their cooperation and effort. Recognition is also due to $\mathrm{S}$ Philip, $\mathrm{S}$ Potter, $\mathrm{T}$ Williams, and $\mathrm{K}$ Amann for skilled technical assistance. This study was partially supported by Invacare Corp (Elyria, OH), Mrs M Francis, and the ASU Graduate Student Research Development Program.

\section{References}

1 Hedrick BN, Morse MI, Figoni SF (1988) Training practices of elite wheelchair roadracers. Adapted Phys Activity $Q$ 5: $140-153$.

2 Coutts KD, Stogryn JL (1987) Aerobic and anaerobic power of Canadian wheelchair track athletes. Med Sci Sports Exerc 19: 62-65.

3 Eriksson P, Lofstrom L, Ekblom B (1988) Aerobic power during maximal exercise in untrained and well-trained persons with quadriplegia and paraplegia. Scand J Rehabil Med 20: 141-147.

4 Flandrois R, Grandmontagne M, Gerin, Mayet MH, Jehl JL, Eyssette M (1986) Aerobic performance capacity in paraplegic subjects. Eur J Appl Physiol 55: 604-609.

5 Gass GC, Camp EM (1987) Effects of prolonged exercise in highly trained taumatic paraplegic men. $J$ Appl Physiol 63: 1846-1852.

6 Okuma H, Ogata H, Hatada K (1989) Transition of physical fitness in wheelchair marathon competitors over several years. Paraplegia 27: 237-243.

7 Gass GC, Camp EM (1984) The maximal physiological responses during incremental wheelchair and arm cranking exercise in male paraplegics. Med Sci Sports Exerc 16: 355-359.

8 Wicks JR, Oldridge NB, Cameron BJ, Jones NL (1983) Arm cranking and wheelchair ergometry in elite spinal cord-injured athlete. Med Sci Sports Exerc 15: 224-231.

9 Sawka MN, Foley ME, Pimental NA, Toner MA, Pandolf KB (1983) Determination of maximal aerobic power during upper body exercise. J Appl Physiol 54: 113-117.

10 Coutts KD, Schutz RW (1988) Analysis of wheelchair track performances. Med Sci Sports Exerc 20: 188-194.

11 Falkel JE, Sawka MN, Levine L, Pimental MA, Pandolf KB (1986) Upper body exercise performance: comparison between women and men. Ergonomics 29: 145-154.

12 Clausen JP, Klausen K, Rasmussen B, Trap-Jensen J (1973) Central and peripheral circulatory changes after training of the arms or legs. Am J Physiol 225: 675-682.

13 Figoni SF (1990) Perspectives on cardiovascular fitness and SCI. J Am Paraplegia Soc 13: 63-71.

14 Hooker SP, Wells CL (1989) Effects of low- and moderate-intensity training in spinal cord injured persons. Med Sci Sports Exerc 21: 18-22.

15 Davis GM, Shepard RJ, Leenen FHH (1987) Cardiac effects of short term arm crank training in paraplegics: echocardiographic evidence. Eur J Appl Physiol 56: 90-96.

16 Sawka MN (1986) Physiology of upper body exercise. In: Pandolf KB, ed. Exercise and Sport Sciences Reviews. Macmillan, New York: 175-210. 
17 Wells CL, Hooker SP (1990) The spinal injured athlete. Adapted Phys Activity Q 7: 265-285.

18 Burkett LN, Chisum J, Stone W, Fernhall B (1990) Exercise capacity of untrained spinal cord injured individuals and the relationship of peak oxygen uptake to level of injury. Paraplegia 28: 512-521.

19 Ellenberg M, MacRitchie M, Franklin B, Johnson S, Wrisley D (1989) Aerobic capacity in early paraplegia: implications for rehabilitation. Paraplegia 27: 261-268.

20 Morris AF (1986) A case study of a female ultramarathon wheelchair road user. Paraplegia 24: $260-264$.

21 Fitzgerald PI, Sedlock DA, Knowlton RG (1990) Circulatory and thermal adjustments to prolonged exercise in paraplegic women. Med Sci Sports Exerc 22: 629-635.

22 Tahamont M, Knowlton RG, Sawka MN, Miles DS (1986) Metabolic responses of women to exercise attributable to long term use of a manual wheelchair. Paraplegia 24: 311-317.

23 Vander LB, Frankin BA, Wrisley D (1984) Cardiorespiratory responses to arm and leg ergometry in women. J Sports Med Phys Fitness 12: 101-106.

24 Sedlock DA, Knowlton RG, Fitzgerald PI (1990) Circulatory and metabolic responses of women to arm crank and wheelchair ergometry. Arch Phys Med Rehabil 71: 97-100.

25 Drory Y, Ohry A, Brooks ME, Dolphin D, Kellermann JJ (1990) Arm crank ergometry in chronic spinal cord injured patients. Arch Phys Med Rehabil 71: 389-392.

26 Coutts KD, Rhodes EC, McKenzie DC (1983) Maximal exercise responses of tetraplegics and paraplegics. $J$ Appl Physiol 55: 479-482.

27 Conley DL, Krahenbuhl G (1980) Running economy and distance running performance of highly trained athletes. Med Sci Sports Exerc 12: 357-360. 